\title{
Attract Force Mathematic Physics Model Release the Formation of Earth Volcano
}

\author{
Yan $\mathrm{Ji}^{1}{ }^{\text {* }}$, Jingzhe Mao ${ }^{2,}$ * \\ ${ }^{1}$ School of Chemistry and Chemical Engineering, Henan Normal University, Xinxiang, China \\ ${ }^{2}$ Higher Vocational and Technical College, Henan Institute of Science and Technology, Xinxiang, China
}

\section{Email address:}

jiyan98@163.com (Yan Ji), maojingzhe@126.com (Jingzhe Mao)

*Corresponding author

\section{To cite this article:}

Yan Ji, Jingzhe Mao. Attract Force Mathematic Physics Model Release the Formation of Earth. Volcano. Earth Sciences. Vol. 6, No. 6, 2017, pp. 127-130. doi: 10.11648/j.earth.20170606.14

Received: August 23, 2017; Accepted: September 13, 2017; Published: October 17, 2017

\begin{abstract}
Volcanoes are a kind of nature phenomena, which are found not only on the Earth, but also on the other solar planets. When erupting, the volcanoes spew rocks, molten lava and plenty of smoke and gases. To find the reason of volcanic formations have caused many researches. Why volcano erupt in mountain body? Why volcano not happen in plain? Why volcano happen in crust plate center or plate edged mountains? This paper analyses the volcanic formation through the Attract Force Model of the mathematical physics. The Model uses rigid balls array to analysis volcano based on finite elements methods. The Model explain the reason of formation of the volcano through the aspect of the mathematical physics.
\end{abstract}

Keywords: Attract Force Equations, Finite Elements Method, Earth Model, Volcanic Formation

\section{Introductions}

Volcanoes are a kind of nature phenomena both on the Earth and other planets [1]. When erupting, the volcanoes spew rocks, molten lava and plenty of smoke and gases [2]. Until now many problems about volcano are still unknown. In this paper that try to explain the reasons of the volcanic formation by building volcano mathematics physics model using the attract force equations and finite elements method.

The classical recognition about the volcano formation based on a series of physical and chemical processes. It is mainly a large amount of radioactive material that exists inside the earth, which decays in the natural state and produces a lot of heat. These heat can be the rock is melted to form a high temperature melting state inside the earth. Once the magma breaks through the earth's crust, it forms a volcano released to the ground, and the temperature rises continuously untilo. The whole process is analyzed from the perspective of thermodynamics theory. When decompression, the cold medium works to the outside world, the temperature must decrease. So volcanoes are supposed to be the heat of radioactive decay that makes the rocks melt and erupt lava.

Recently some scholars said (Li Hongye, 1993) proposed the Earth poles extrusion, unravel the mysteries of the earth's development, he thinks that under the effect of the extrusion pressure between, the earth's equator shaft expansion form of longitudinal tensile fracture and zonal extrusion, global volcanoes are mainly distributed in warp and weft structural belt.

Based on predecessors research works, this paper used finite elemental methods to build earth attract force model, and release the volcano formation processes. The attract force model well explained the volcano dynamic reason, which proposed a kind of theory for volcano formation.

\section{Model Build}

Firstly building the rigid balls arrays to simulate the internal earth based on finite elements method. The weight of $11 \times 11$ rigid balls built arrays is one kilogram. The distance between two balls is 1 meter. 25 rigid balls were put in the triangle arrays to simulate mountain body (Figure 1 insert), and use the Newton equations of the gravity deduction $[\mathrm{F} / \mathrm{G}=(\mathrm{M} 1 * \mathrm{Mx}) / \mathrm{R} 1-(\mathrm{Mx} * \mathrm{M} 2) / \mathrm{R} 2]$ to calculate every balls received attractive force as parameter $\mathrm{F} / \mathrm{G}$ [3]. To mark the calculated vectors' arrows and values on the balls array (Figure 1). This is the internal mountain attractive force model 
to release the volcanic formation, that as attract force mathematical physics (AFMP) model has been used to explain galaxy black hole [4], solar light [5], and earth river source [6].

\section{Results and Discussion}

\subsection{Model for Volcano}

The results of the calculation of the model show the internal earth attractive force arrows directions' situations (Figure 2). The inside of the earth receives outwards attractive force
(OWAF), and the layer of the surface of the earth receives inward attractive force (IWAF) from the direction to the internal earth. The surface IWAF makes the matter down, gathers, and crushes into the earth. The internal OWAF makes the matter outwards direction moves. The inner surface matters interact with outer internal parts form the convective layer in mantle. The molten lava in mantle convective current layer has inner and outer moving directions so that it balances the mantle and the convective current.

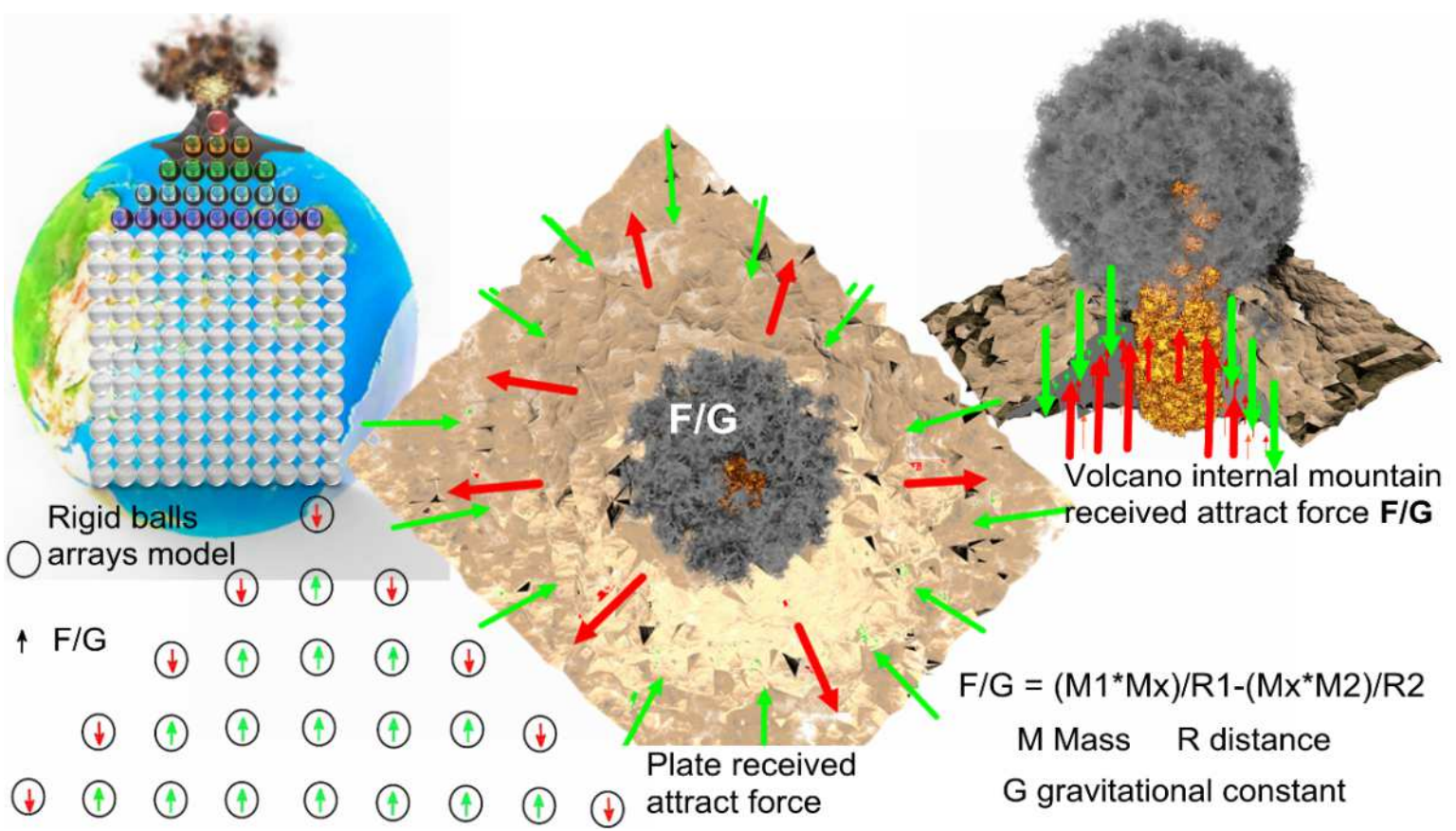

Figure 1. The deduction is that the equations of the attractive force mathematical physics model (AFMP model) release for volcano forming reason. The arrays built by rigid balls calculate inner volcano attractive force situations based on finite element method (left). The areas of the plate center received scattered attractive force (middle). The self-mass of the mountain attracts molten lava to the upward flow (right). These figures of the crust plate and the volcano show the attractive force situation $(F / G)$ of internal volcano mountain. The directions of the $F / G$ arrows release the reasons of the formation of the volcanoes.

The internal mountain parts have also received OWAF, and the mountain surface received IWAF (Figure 3). The mountain attracts the internal molten lava throughout the earth layer during a long period of OWAF. When the balance between the inner and the outer is destroyed by some event, such as earth quake [7], or solid tides [8], the molten lava erupts so that it forms the volcano. The inner mountain parts receive accelerated attractive force from deep underground to the inner parts of the mountain peaks. This means the molten lava receives accelerated attractive force from the foot of the mountain to the peaks. Once the balance is broken, the molten lava will rush out of mountain.

It is noted that the peak of the surface of the mountain IWAF is lower than the sea level of the common earth surface IWAF. While the inner peak of the mountain gets the OWAF strength is larger than the sea level. So it is more easily the molten lava erupts through the mountain than through the plain domains. So the volcanoes form through the mountain. It is difficult to erupt the molten lava through the plain areas.

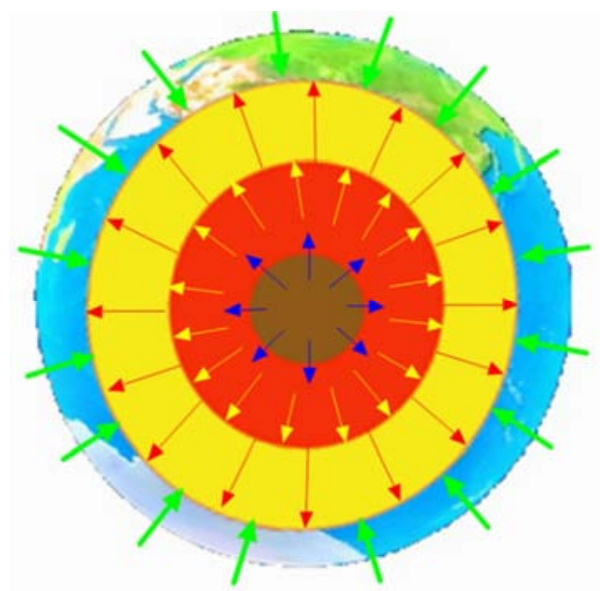

Figure 2. The attractive force directions showed the situation of the inner part of earth. The arrows represents the directions where the mountain receive attractive force. The length of arrows represent the relative strength of attractive force. The inner part receive the outer attractive force. The surface parts receive the inner attractive forces. These situation are deduced from attractive forces mathematical physics model (AFMP model). 


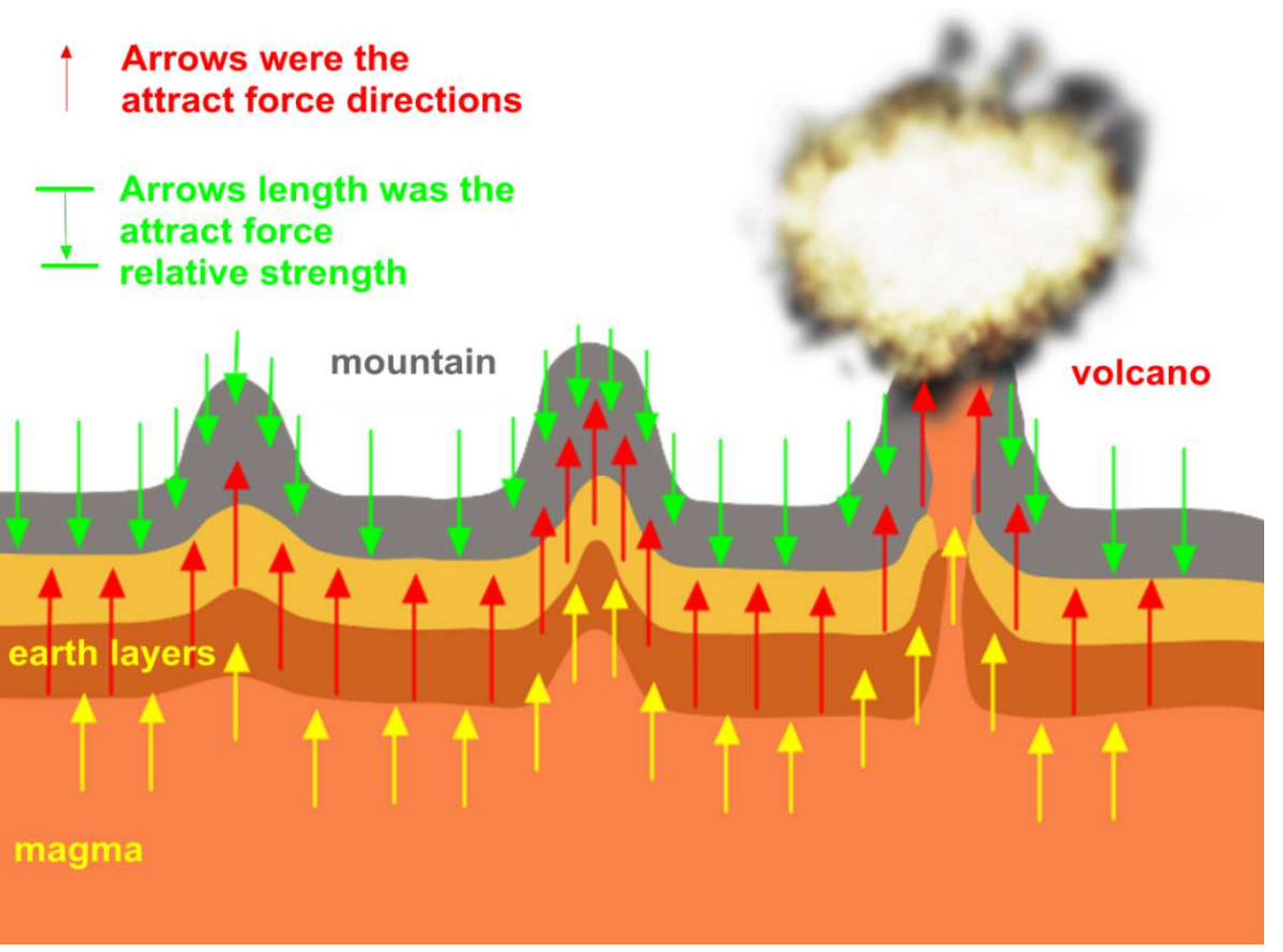

Figure 3. The forming processes of the volcano. The down/upward attract force (arrows) balance losing to form volcano. This illuminate is deduced from AFMP model.

Compared the probability on mountains formation volcanoes, the earth crust plate center or edged mountains were easier to be volcano than other parts mountain on the same plate. One whole earth crust plate can be regarded as one body. The body can be analyzed by the mode of the mathematical physics of the attractive forces. The inner plate receives OWAF. The edged plate receives IWAF. So the center plate of the mountain receives the attractive forces from the vertical directions. At the same time, the plate center receives outward scattered attractive forces at the directions of the sea level. So the center plate gets upward and scattered attractive forces so that it forms the crater and it is very easy to erupt the molten lava. The edged plate mountains are on the split earth layers. The layer of the molten lava is shallow so that OWAF makes it easily to form volcanoes.

\subsection{Volcano Examples}

Cite Yellowstone Park as an instance. Yellowstone Park in North American plate center [9], Yellowstone Park locates at Wyoming, which exits at center area or North American plate. The North American plate self-mass attracts molten lava flowed upward. Based on the model, the center areas of the North American plate also get scattered attractive forces to form the holed structure crater. It also makes the channel for molten lava easily to erupt. So the Yellowstone volcano is the center area of the volcano at North American plate, which can be explained by the AFMP model.

Cite Hawaii volcano in center of Pacific plate as the second example. The Pacific plate huge mass attractive forces attract the molten lava of the earth layer to the upward. The Pacific plate self-mass action makes the center part of plate get scattered attractive forces. So the Hawaii areas form the holed crater and it is easily to erupt molten lava. So the Hawaii volcano forms the center of Pacific plate. The AFMP model can best explain the formation of Hawaii volcano.

Cite Fujiyama volcano in center of Japan plate as the third example. Japan locates between the edge of Asian-Europe plate and Pacific plate. The crustal motion is active and plenty of earthquakes happen there. Japan Island form the Japan plate. This plate self-mass attracts molten lava upwards. And the center areas of Japan plate get scattered and attracts force to form the holed kinds of channel. The molten lava through the plate center channel erupts. Then it forms Fujiyama volcano, which can be best explained by the AFMP model.

Cite Indonesia plate center volcano as the fourth example. Indonesia locates between the three plates (Pacific plate, Australian plate and Indian Ocean plate). The Indonesia exists more than 400 volcanoes. Indonesia is an island country. Every islands have volcanoes. Island might be regarded as one mountain in sea, which island self-mass attracts molten lava to move upwards. Further Indonesia is on the plate edges, the earth layers are active. The layers of the molten lava are shallow. The molten lava is easily to flow upward through the plate edges. The self-mass of the mountains in Indonesia attracts molten lava to flow upwards. So because of these factors, it forms many volcanoes in Indonesia.

Cite Mediterranean plate center Vesuvius volcano as the fifth example. Mediterranean plate locates between the edges 
of Europe plate and Africa plate. Vesuvius volcano locates at center of Apennines, which are at center of Mediterranean plate. Analyze Mediterranean plate center Vesuvius volcano by AFMP model, the Mediterranean plate self-mass attracts deep molten lava to flow upwards. The Mediterranean plate center receives scattered attractive forces to make the Apennines center areas crater and form one upward channel. The motion of the geology is active. When the balance of the upward and downward is destroyed. So it forms the Vesuvius volcano erupt. The AFMP model can best explain the formation of Vesuvius volcano in the center of Mediterranean plate.

These earth volcanoes are always at the plate center mountain. When geological event induces volcano losing inwards/outwards (or down/upwards) attractive force balance and then erupts molten lava. It is the same as Changbaishan [10] mantle upwelling. Mantle upwelling have been observed, the Changbaishan mountain self-mass form attract force to attract mantle magma upwards flow, then form mantle upwelling. The deep mantle were received upwards attract force, the earth crust surface received downwards attract force. The mountain Changbaishan self-mass changed the balance of down/upwards, then forming channel of volcano. Now the Changbaishan mantle upwelling have been observed, which can be an example to prove the AFMP model.

It can be hypothesis that if remove volcano's mountain body, which means man-made remove plate center's mountain to be plain, then there might be no volcano erupt in these areas. The removed mountain that changes into plain model, the removes mountain mass no longer produce upwards attract force, so people are safe on the plain.

\section{Conclusion}

By using the mathematical physics (AFMP) model of the attractive forces explains the reasons of volcano formation on the Earth. Volcanoes erupt when mountain surface IWAF Vs. The inner OWAF balance loses. The plain model keeps inward/outward balance more stable and safe than mountain model. The domains of the earth plate center and the edges of the mountains are easier to become volcanoes. Maybe human manmade remove the bodies of the volcano mountains might stop volcano erupting in the future. This AFMP model will help scientists to research earth physics and astronomy.

\section{References}

[1] Witze, Alexandra, Ancient volcanoes exposed, Nature, 2017, 543(7645), 295-296.

[2] Whitchurch, Amy; Newton, Alicia. Volcanoes past and present, Nature Geoscience. 2015, 8(4): 251-251.

[3] Yan Ji. The attract force equation of energy. American Journal of Modern Physics. 2014, 3 (6), 224-226.

[4] Yan Ji. Galaxy center mathematics physics model deduce black hole to be empty holes structure. http://science.sciencemag.org/content/345/6192/64/tab-e-letter s

[5] Yan Ji. Sun structure mathematic physics models release solar lights emission, proton event, jets, and cool atmosphere. Global Journal of Science Frontier Research: A, 2016, 16 (4), 1-3.

[6] Yan Ji. Earth Internal-Mountain Water Model Release: Water can Flow Upwards. Earth Sciences. Vol. 6, No. 2, 2017, pp. 10-14. doi: 10.11648/j.earth.20170602.11.

[7] Ian Randall, How Earthquakes can trigger faraway volcanoes, Science, 2016, 352(6285), 498-498.

[8] Middlemiss, R. P.; Samarelli, A.; Paul, D. J.; Hough, J. ; Rowan, S. ; Hammond, G. D. Measurement of the Earth tides with a MEMS gravimeter, Nature, 2016, 531(7596) 614-617.

[9] Huang, Hsin-Hua; Lin, Fan-Chi; Schmandt, Brandon; The Yellowstone magmatic system from the mantle plume to the upper crust, Science, 2015, 348(6236): 773-776.

[10] Tang, Youcai; Obayashi, Masayuki; Niu, Fenglin; et al. Changbaishan volcanism in northeast China linked to subduction-induced mantle upwelling, Nature Geoscience, 2014, 7 (6): 470-475. 